Article

\title{
Religion and Relationships in Muslim Families: A Qualitative Examination of Devout Married Muslim Couples
}

\section{Zahra Alghafli, Trevan Hatch and Loren Marks *}

School of Social Work, Louisiana State University, 311 Huey P. Long Field House, Baton Rouge, LA 70803, USA; E-Mails: zalgha1@tigers.lsu.edu (Z.A.); thatch8@lsu.edu (T.H.)

* Author to whom correspondence should be addressed; E-Mail: lorenm@lsu.edu; Tel.: +1-225-578-0433.

Received: 17 March 2014; in revised form: 24 July 2014 / Accepted: 4 August 2014 / Published: 15 August 2014

\begin{abstract}
Since 11 September 2001, Islam has been the center of many debates, discussions, parodies and publications. Many Muslims feel that their religion has been portrayed unfairly in Western media. The topics that seem to generate the most criticism relate to gender roles and the treatment of women, both inside the home and in society. The purpose of this paper is to examine the perceived role of Islam on marital and familial relationships from an insider's perspective and to present participants' reflections on sensitive issues, including gender roles, women's rights and marital unity. Content analysis of in-depth interviews of twenty diverse Shia and Sunni Muslim couples living in the U.S. $(n=40)$ yielded three emergent themes: (1) Islam as a way of life; (2) Islam as a unifying force; and (3) gender roles and the treatment of women. These data suggest that, as perceived by our religiously involved “insider” participants, Islam influences marriage relationships, unites families and (when understood and lived properly) protects women from abuse and oppression.
\end{abstract}

Keywords: family; Islam; marriage; Muslim; qualitative

\section{Introduction}

Empirical research on religion vis-à-vis the family has seen a substantial increase over the past fifteen years or so, and numerous correlations between variables of family and religion have been identified [1-5]. Researchers, however, have recognized that research on religion and family life 
remains at an infancy stage in many ways [6]. Even more apparent is the dearth of empirical research on Muslim families, especially in North America.

The current Muslim population in the U.S. and Canada is approximately 3.5 million and is projected to more than double over the next two decades. Many Muslims in this region are African Americans or immigrants from South Asia, the Middle East or North Africa, which makes them both ethnic and religious minorities [7] Since 11 September 2001, anti-Islamic hate crimes jumped an astounding 1650\% (almost seventeen-fold) in the U.S., and research has reported that Muslims still feel a lack of cultural safety in the U.S. [8,9]. On the other hand, the image of Islam may be improving in the U.S. based on other research. For example, since 11 September 2001, roughly 20,000 people in the U.S. have converted to Islam each year. Of these 20,000 per year, 15,000 are women [10]. A recent survey of 39 counties revealed that a majority of Muslims are deeply devoted to their religion [11], and therefore, it may be the case that the religious beliefs and practices of Islam significantly impact marriage and family life. Familial issues regarding Islam that seem to dominate much of Western media, mostly in a negative light, are gender roles and the treatment of women [12]. Based on the above data, the Muslim population remains an important demographic to study for researchers of religiously involved families.

This paper answers the call of religion and family scholars who have urged researchers to examine more thoroughly the role of religion on families of the various minority religious traditions (i.e., non-Christian), and to rely more on qualitative data $[1,5,13]$. The purpose of this paper is to examine the role of Islam on marital and familial relationships and to present our participants' reflections on sensitive issues, including gender roles, women's rights and marital unity.

\section{Overview of the Literature}

Empirical research on religious families indicates that religious involvement, particularly when shared by both marital partners, generally has significant positive influences on various aspects of marriage and family life, including marital fidelity, marital satisfaction, forgiveness, conflict resolution, physical and mental well-being, self-esteem, life satisfaction and longevity [2,3,14-16].

After analyzing 184 studies (1999-2009) on various connections between religion and family life, Mahoney suggested that researchers must narrow their foci as they move forward [5]. Specifically, for example, she identified a need to examine nontraditional families, religious and ethnic minority families and to use more qualitative and high-quality quantitative (e.g., longitudinal) methods. In addition to Mahoney's suggestions, Marks and Dollahite have recommended that researchers not only continue investigating the "whats" of the religion-family interface, but also to drill deeper and illuminate the "whys" [3,17,18]. In the spirit of this petition, Dollahite and Marks developed a more refined framework for studying religious families that is based on three key conceptualizations of "religion": (1) faith community; (2) religious practice; and (3) spiritual belief [19,20]. Faith community refers to "support, involvement, and relationships rooted in one's congregation or less formal religious community” ([20], p. 375). Religious practice refers to an outward expression of faith (e.g., prayer or study of sacred texts), including religious-based abstinence of various types. Spiritual belief includes any belief or perspective that is sacred and/or faith-based. For the purposes of this paper, we will focus 
on two of the three conceptualizations of religion vis-à-vis marital relationships: religious practices and spiritual beliefs. ${ }^{1}$

\subsection{Religious Practices and Marriage}

Research on religion and marriage has identified correlations between religious practice and enhanced marital quality, especially when those practices are shared [21]. Mahoney et al. found that couples who pray for each other and attend religious services together seem to experience better marital quality [22]. Shared religious practice also appears to help couples with preventing and resolving marital conflict [23]. Marks and colleagues suggested that a positive use of prayer by a married couple, such as when they pray for the betterment of each other, is more likely to result in desirable outcomes [13,24]. A qualitative study examining devout Christian, Jewish and Muslim families revealed that prayer is a central practice of all three religious groups [20]. Research by Butler, Stout and Gardner found that prayer, among other things, "enhanced experiences of emotional validation; promoted accountability toward deity; de-escalated negative interaction, contempt, hostility, and emotional reactivity; enhanced relationship behavior; facilitated partner empathy; increased self-change focus; encouraged reconciliation and problem-solving; and promoted a sense of guidance from God” ([25], p. 10).

Studies have also shown, however, that religion can be associated with negative outcomes. Prayer, for instance, can be utilized negatively and in ways that tend to harm relationships; for example, to ask God to change fundamental characteristics of their partner that are perceived to be "bad" [26] Mahoney, Pendelton and Ihrke highlighted both positive and negative types of religious coping [27]. A positive process facilitates healthy adaption that enables couples to overcome hardship, while negative coping is characterized by spiritual struggle that can dampen marital relationships and reduce the level of marital satisfaction. Conflicting or problematic religious beliefs or practices may also result in more marital relationship problems [28]. Thus, researchers have shown that religious practices may be both helpful and harmful to individuals and couples [1,29].

\subsection{Spiritual Beliefs and Marriage}

Research, including a 94-study meta-analysis, has shown moderate to strong correlations between both religiosity and marital commitment and satisfaction [30,31]. In one attempt to understand the relationship between marriage and spiritual beliefs among Christian, Jewish and Muslim families in the U.S., Marks found that spiritual beliefs may influence marriage through several channels, including anti-divorce beliefs and shared religious beliefs in general [15]. Other qualitative studies have shown that couples who reported a belief in God's involvement in their marriages also reported greater marital commitment and satisfaction [32,33]. Two additional qualitative studies found that shared faith, including beliefs, was one of the most important resources for religious couples in maintaining

\footnotetext{
While involvement in a faith community, including the social support that accompanies such involvement, may also be relevant to family functioning and marital relationship quality, we do not emphasize this aspect of Islam in this paper because in order to treat the topic with appropriate depth the topic requires a separate article which we plan to write in the future.
} 
strong marriages [34,35]. Quantitative studies have also reported that couples who perceived their marriage as "sacred" experienced lower levels of marital conflict and higher overall levels of marital satisfaction [22]. Indeed, Burr and colleagues posited in their recent volume, Sacred Matters, that viewing any aspect of life as "sacred" endows it with unique power and force, but that this may be especially true with marriage and family relationships, as Mahoney has documented [1].

\subsection{Muslim Families}

Much of the existing research on religion and family is based on Anglo-Saxon and Judeo-Christian participants [3]. Very little empirical research has been conducted on the Muslim population, with the exception of recent work in the Middle East by Abdel-Khalek. The few studies that have been conducted on Muslim samples found that Muslims who are religiously active tend to be moderately happier, healthier and less depressed than those who are not religiously active and involved [29].

In attempts to understand the relationship between religiosity and subjective well-being, happiness, self-esteem, quality of life and life satisfaction among Muslim populations, Abdel-Khalek, a professor at Kuwait University, conducted a series of rigorous studies using large Muslim samples from several Islamic countries, including Algeria, Egypt, Kuwait, Lebanon, Palestine, Qatar and Saudi Arabia. Key findings from Abdel-Khalek's research include the following: (1) two studies of Kuwaiti college students $(n=2210)$ and adolescents $(n=6339)$ revealed a significant positive correlation between self-reported happiness and personal religiosity [36,37]. These studies also provided evidence that religiously-active Muslims were happier than their less religious counterparts and experienced lower levels of anxiety and depression; (2) a 2010 study of a Kuwaiti sample of adults, ages 18 to 31 ( $n=487$ ), found that those who reported high religiosity were healthier, obtained higher subjective well-being and scored lower on neuroticism than their less religious counterparts [38]; and (3) additional examinations of samples from Egypt and Kuwait concluded that individuals who are happier, healthier and experience better mental health tend to be more religious than their counterparts [39-41].

Abdel-Khalek joins a small body of researchers who have conducted empirical studies on the Muslim population. However, most of these studies have primarily focused on individual religiosity and well-being [42-44]. Further, many of them examined gender-role attitudes among Muslim women or women's role in society [45-49]. Very few research studies have examined the relational aspects of Muslim families and the perceived benefits of Islam for marriages. While the field of religion and family, especially pertaining to Islam, remains open to additional psychological studies and research that approaches families and individuals from a pathogenic approach, the field is hungry for research on family relationships from a salutogenic or strengths-focused approach, as well. This paper adds to the nascent field of Muslim family life, as it examines the relational aspects of Muslim couples and the perceived role of Islam on their marriages. As a result, the present study is novel in a number of ways, including: content (in-depth data from Sunni and Shia Muslim families); race/ethnicity (a variety of minorities are represented); the unit of analysis (marital/familial/relational instead of individual/psychological); perspective (strengths-focused instead of deficit/pathogenic); and the research method (in-depth qualitative instead of quantitative). We now turn to a discussion of the latter issue, the method. 


\section{Method}

Research about families and religion has typically been conducted by scholars employing demographic and quantitative approaches [13]. By contrast, the current study is an attempt to understand the connection between family and religion using an in-depth, interview-based, qualitative method. In qualitative methods, the purpose is not to identify structural or demographic trends in families, but rather "the focus is on the processes by which families create, sustain, and discuss their own family realities” ([50], p. 4).

\subsection{Sample}

The primary focus in most qualitative research, including the present study, is to obtain data with richness and depth. Thus, the sample in qualitative research is likely to be intentional and purposive instead of random [51]. The purposive sample of this study includes religiously involved Muslim husbands and wives who reportedly view their religion as a meaningful aspect of their marital and family relationships.

The current study employs two combined samples. The first sample of data was collected by the third author and colleagues who interviewed 14 Sunni Muslim couples. The second sample was collected by the first author with six Shia Muslim couples or a combined sample of 20 couples. ${ }^{2}$ The combined sample was richly diverse in terms of: (1) age (early 30s to early 60s); (2) race/ethnicity (including African/African American, Arab/Arab American (from Iraq, Jordan and Palestine), European American, Indian (India) and Iranian participants); and (3) socioeconomic status (education levels ranged from not completing high school to completing Ph.D./M.D. degrees).

\subsection{Design and Procedures}

We employed a grounded theory design that allows for the emergence of themes and core concepts while analyzing data that can be used to build microtheory and conceptual models [52]. First, the participants' written consent form and demographic summary were obtained. Second, a semi-structured interview with about 30 open-ended questions was conducted. The questions were based on significant elements of faith and family life, including: “(a) Origins, Costs, and Benefits of Religious Involvement, (b) Positive Parental Role Types in Comparison, (c) Religion and Identity Formation and Role Construction, (d) The Influence of Family on Religious Involvement, and (e) Religion as a

2 The purpose of this paper is not to compare and contrast Sunni and Shia Muslims, but to be inclusive of both major branches expressions of Islam. In brief overview, however, both Sunni and Shia Muslims share most fundamental Islamic beliefs, practices, and rituals. Both agree on the main Islamic pillars involving the reality and nature of Allah (God) and Mohammad's prophetic calling and mission. Both branches pray five times a day (salat), fast one month every year (Ramadan), give money to the poor (zakat), and follow the same book (Quran). The major issue of controversy between these two sub-groups involves the nature of religious authority. Disagreement arose as to who was to take over the leadership of the Muslim nation after the Prophet Mohammed died. Sunni Muslims agreed that the Muslim leader should be elected by the majority. This is what was done, and Prophet Muhammad's father in law, Abu Bakr, became the first Caliph of the Islamic nation. By comparison, Shia Muslims believe that the Prophet appointed his son-in-law, Ali Bin Abi Taleb, as the most knowledgeable individual after him and assigned everyone to follow him. 
Meaningful Familial Influence” ([53], p. 32). Interviews were conducted with both the husband and wife present. The length of the interview varied from couple to couple with an average length of about two hours. With each question, both the husband and wife were given an equal opportunity by the researcher to answer. In some cases, due to the nature of the interview, follow-up questions were used to clarify and understand the ideas, concepts or events.

All of the interviews were digitally recorded, then transcribed verbatim. They were then saved as Microsoft Word documents to create a data audit trail [54]. Copies of the transcripts were then given to the participants as a member check. Transcribed interviews were coded to identify salient and recurring themes and categories across interviews [55]. According to Strauss and Corbin, open coding of the interviews is the first analytic step for examining the data [52]. Concepts were identified from the narrative data. Axial coding, as the next step in the analytical process, involves numeric content analysis (NCA) of the concepts identified during open coding. High frequency concepts, as well as salient concepts, were organized thematically. These emergent themes provided the researchers with insight as to what religion-family issues matter to the participants and why they matter. It must also be noted that although we were able to identify several concepts during this exploratory study, we do not believe that we have approached, much less reached, theoretical saturation. We intend to increase our sample over the next several years to continue to delve and explore.

\subsection{Reflexivity}

Reflexivity refers to the potential of the researchers' biases and predispositions to influence the result of the study when collecting, analyzing and interpreting data [56-58]. We embrace the practice of revealing biases and experiences that relate to the data being considered and in the spirit of transparency and authenticity share the following: the first author is a highly religious Shia Muslim, and the second and third authors are both highly involved in The Church of Jesus Christ of Latter-day Saints. Further, all three authors (like the participants in the study) are involved in marriages of seven years or more and are themselves parents.

With the above noted, and in an effort to avoid imposing a potential bias highlighting benefits of religion and family life, questions related to the challenging and difficult aspects of life that a religious Muslim encounters were also included in the instrument, and related data will be reported in this manuscript in an effort to achieve a balanced picture of religion and family life, as promoted in recent work $[1,26,59]$. With this context offered, we now turn to the emergent themes that comprise our findings.

\section{Findings}

Our primary aim is to present, with relatively little commentary, our participants' first-hand comments and reflections on the role of Islam in their marriages. Our open coding of the in-depth interviews yielded three emergent and salient themes:

(1)“Every word that you speak...”: Islam as a Way of Life. This theme highlights the idea that Islam guides every aspect of life, including many smaller details. By following Islamic law, particularly as it was revealed to the Prophet Muhammad and preserved in the Quran, an 
individual, couple or family will have direction regarding how to act and how to interact with other people.

(2)“Togetherness is not limited to this world”: Islam as a Unifying Force. This theme emphasizes that Islam, if followed properly, can reduce conflict and oppression and unify families. Proper adherence to and understanding of the doctrines and principles of Islam will not only decrease conflict and oppression in this life, but it can also increase the divine rewards for the entire family in the afterlife.

(3)“Rights, roles and responsibilities”: Gender Roles and the Treatment of Women. This final theme discusses issues primarily relating to women and their roles in the home. Illustrative and representative comments and reflections drawn directly from the primary data will be presented under each theme.

\subsection{Theme 1: "Every Word that You Speak": Islam as a Way of Life}

Several interview questions were asked to ascertain the role of Islam, as a belief system, in family life. Almost all participants mentioned that Islam either directly or indirectly affected how they live their lives, especially in relation to their families. Many commented that Islam plays a vital role in promoting marital stability, security and happiness. The following five excerpts illustrate the salient belief that Islam guides every aspect of life:

Mokthar (Shia husband) ${ }^{3}$ : Understand[ing] the authority over us...[is] the secret to our marriage... That is the authority of God.

Ali (Shia husband): [Islam] is the book that shows us how to live and survive.

Alex (Sunni husband): Islam is a religion of rules. Sometimes we call [Islam] "a way of life" because it guides you in every aspect of your life, even in places where other religions don't specify anything. [In Islam] you have specific guidelines. Those guidelines help resolve conflicts between parents, between husband and wife, father and children, in almost every aspect.

Kim (Sunni wife): Everything is affected by your traditions and by your practicing [Islam], every breath you take, every moment that you live, every word that you speak, every opportunity that you have to interrelate with other human beings...

Ahsan (Sunni husband): As Muslims, religion is not separate from the way you live your life.... The way you behave with people is part of your religion. The way you drive your car is part of your religion. It affects your behavior.

Many of our participants, as articulated above, commented that Islam is a manual for how to live life in totality. Indeed, the ideal is that one need not consult outside sources-e.g., non-Muslim philosophers, therapists or other relationship experts - for guidance on the proper ways to interact with people and to conduct life in the home. Whether this ideal actually plays out in Muslim households is

3 All names have been replaced with pseudonyms to protect anonymity and identity. 
not the objective of this study; however, it is clear that the concept, "Islam as a way of life", is (at the very least) given extensive lip-service by our participants.

As an aside, we noticed that husbands seemed to comment more than wives on broad questions relating to Islam (notice that four of the five reflections above were provided by men). This suspicion lead us to randomly select eight of the twenty interviews to examine further, wherein we found that husbands provided more information than wives in six of the eight interviews on the following (fairly broad) questions: "Did your religious beliefs and values influence how you met and decided to marry?" and "What are some of your deepest spiritual beliefs relating to marriage?" As the topics became more focused-specifically regarding gender roles or misconceptions about Islam-women seemed to increase their participation and commentary. They seemed to be more assertive in broaching sensitive topics and commenting more directly about related issues, including topics like wearing hijab (i.e., the veil that covers the head, neck and chest), as demonstrated later in connection with Themes 2 and 3. For example, in these same eight interviews, we found 106 references to the terms, "women” (86), "hijab" (8), "gender" (8) and "roles" (4). Only 38\% of these references appeared in the comments provided by husbands.

Some of our participants provided specific examples of how Islam influences every aspect of life. Orhan (a Sunni husband), for instance, explained that Islam even informs decisions on mate selection:

Prophet Mohammad, peace be upon him, gave criteria for the marriage. He said...if you are going to choose a girl, and you have different alternatives, like there is a beautiful woman, another one is rich, very rich, another one is very noble, and the other one is very pious and religious-choose the last one. So I think this [type of guidance] is almost in every aspect of Muslim's life... I think that affected my [marriage] decision, and the way we met also.

Another participant similarly commented on how Islam influences the process of selecting a mate:

Burku (Sunni husband): First of all, the most important thing in our marriage is what [Islam] says about marriage... Instead of how she [potential wife] is rich, or how she is beautiful, or how her family has high level of occupation or a rank, [I must focus on]... what kind of faith she has. [Her]...faith, the religion, is the most important thing.

Most of our participants explained that Islam, as revealed by God through the Prophet Muhammad, is a powerful force in reducing conflict and unifying married couples, the topic of Theme 2, as addressed next.

\subsection{Theme 2: "Togetherness is not Limited to this World": Islam As a Unifying Force}

The theme of "togetherness" was often discussed in the context of engaging in religious activities as a family. Participants frequently mentioned prayer as an activity mandated by Islam that tends to unite the family. Some participants discussed prayer as a means to reducing conflict, as illustrated by the following reflection:

Omar (Sunni husband): When you pray you have to center yourself and...submit to Allah. You can’t be angry and submit. It just does not work... Especially after prayer...the whole 
house [will] settled down. There is no TV, there is no internet, there is nothing, and there is pureness of communications there and it comes straight from the heart. You know, you just can't get that any other way...especially [the] close[ness] with the children.

Other participants explained that prayer provides opportunities for frequent family interaction. Ashekah (a Sunni wife), for example, shared her feelings about the importance of family prayer by reflecting that:

[Prayer] is something we do as a family. You are worshipping as a family and it gives everybody time to stop and interact with each other afterwards. And you know, you're teaching your children something that is good. You are worshipping God and that, to me, is heartwarming because we are all there... So to me, it's good. It seems like a family time.

Mohammed, a Sunni father of two, explained:

Prayer in Arabic is called salat. What does salat mean? It means connection, it is your time to connect with God.

Indeed, for Asheka, Mohammed and many other families, salat seemed to enhance connection not only with Allah (God), but also among wife, husband and children.

Fasting was another frequently mentioned shared religious practice in the interviews. Aliyah (a Sunni wife), while generally discussing the role of Islam in her marriage, mentioned fasting as one example of religious agreement between her and her husband. She stated:

I think that religion affects our married life because in this point we can agree, and we spend some time without arguing. For example, when we both fast, we do our activities together. We break the fast together [and] we wake up midnight and eat before fasting. So we do these types of things together... At this point we again agree and that's how religion is making our life going together and growing together.

Although Aliyah's implicitly reveals that her marriage involves some "arguing", note that in Aliyah's brief excerpt, she uses the word "agree" twice and "together" five times in reference to her husband and marriage, in connection with fasting. It also seems significant that Aliyah opens with the first person singular ("I"), but then quickly shifts to the plural and marital "we", which she invokes no fewer than eight times in four lines. These patterns are consistent with Theme 2's emphasis on unity through shared faith practices.

Several couples remarked that in addition to prayer and fasting, discussions about religion help unify the marriage, because the discussions facilitate and enable couples to develop a congruous understanding of Islam. Hashim (a Shia husband) illustrated this in the following excerpt:

When we get a chance we pray together, that is important for both of us... I think that is the most important thing... [Also], after prayer we would have a religious session... Whenever something comes to my mind or to her mind or something brought up by others, we talk about it. That is also really good for both of us. What I can say is that although we have lots of similarities in general ideas, sometimes our minds act [in ways that are] complementary. So she looks at things in a specific way that I don’t. And I look at things in a totally different way, although we have the same belief, our ideas sometimes are different and 
complementary. So that also has a good effect on [us]... When we talk about [different ideas], I think most of the time we can convince each other and come to an agreement.

Like Aliyah earlier, notice that Hashim selects the word "we” eight times as he describes a shared religious practice (in this case, "praying together") as something "that is important for both of us" (“us” appears three times).

Participants, in addition to discussing family unity in the context of shared religious practices, as illustrated by the previous reflections, also commented on marital unity in the context of spiritual beliefs. Islam's teachings about the importance of family and marriage, both in this life and in the afterlife, may give couples a unique and salient perspective that sustains them through the hard times and generally strengthens their relationship. The following two excepts capture and illustrate this idea:

Bruku (Shia husband): If [couples] really are touching each other['s lives], especially in spiritual way, they are really continuing their life together in hereafter... If spouses are in [the] same place and spiritual level, they will be allowed to continue their life together in [the] hereafter. I think this is the deepest thing that influences my marriage, that we both believe in. If I am going to mention one thing, that will be the one.

Maytham (Sunni husband): Marriage or the family should be like a heaven in this world, you know. It should be like living a heavenly life, and also to prepare for the hereafter. When we marry each other, we think our togetherness is not limited to this world, we are like the soul mates and even after we die we will be together.

This shared spiritual belief that marriage can endure forever (and the power it can have) has been referenced by wives and husbands in previous qualitative work with other highly religious families from other world faiths, as well (i.e., Mormon, Greek Orthodox) [20].

Another spiritual belief of Islam is that religion practiced with the family is worthy and deserving of more reward, blessings and benefit in the afterlife than religion practiced individually. This doctrine encourages couples to worship together. The three following comments provide insight into this spiritual teaching and its influence:

Orhan (Sunni husband): We believe that "together-prayer" has more rewards than just praying individually. So, this is one thing husband and wife can do together to increase their rewards...in the afterlife.

Hashim (Sunni husband): It is statutory in our family that if you pray by yourself, you get some [benefit], but if you pray with your family, you get more [benefit]. It's also social, you know, you feel more comfortable when you pray with your wife and when you pray with your children. It's [provides] a unity, you feel more comfortable when you pray together.

Rehkah (Sunni wife): Marriage is one of the most virtuous or most spiritual foundations in society. It is a very religious thing for me. And we think of it as one of the traditions of our Prophet, so it's a very spiritual thing... We have a lot of traditions that say when a man and wife get together, [when] they marry, they have actually started a foundation. And both of their faiths become complete. For example, the worship that you used to do when you were single [is] so much more, worth more, after you are married. So [it] really increases the 
value of your faith, when you are married. We think of it as a way to progress spiritually.

We become partners in growing religiously.

Even though Islam teaches that marriage is a spiritual companionship and that equality within the marriage is essential for maximizing happiness for both genders, many misconceptions about gender roles and the treatment of women in Muslim countries and households are perpetuated by non-Muslims, as well as by various segments within Islam. This topic is where we now focus our attention in our third and final theme.

\subsection{Theme 3: "Rights, Roles and Responsibilities": Gender Roles and the Treatment of Women}

The issue of women in Islam vis-à-vis the family was among the most frequently mentioned of topics in the interviews. Several female participants were assertive on this matter and spoke plainly and passionately about it. Many of them shared lengthy reflections on Islam's teachings about gender equality and gender roles, as well as on the many misconceptions about the treatment of women within the Muslim community. However, gender "equality" is a difficult topic, because it forces those in dialogue to define their terms. What exactly does it mean to be equal? The answer to that question varies among cultures and religions; and (as we learned) it also varies among commentators within the same religious milieu. Several of our participants (men included) offered their perspective of gender equality within the context of Islam. Burku, a Shia Muslim husband, explained that "we are equal, but we have our own responsibilities to fulfill.” The word "responsibilities” in relation to the genders was mentioned by several participants. Kim, an American-born convert to Sunni Islam, offered perhaps the most detailed and illustrative comment about the different "roles, rights, and responsibilities" of men and women as defined by the faith:

He has rights over me and I have rights over him, so as he has the responsibility to provide for the income, I have the right to be provided for. And I think there is a good balance in that... Sexual things are [also] guided in Islam, we have rights on each other, responsibilities on each other, time spent with each other is also a responsibility and a right... You have rights and roles and responsibilities that are very much written about in Islamic religion. So, if you adhere to your rights, roles, and responsibilities in a perfect world, you avoid all the conflict.

[Women] have prescribed rights and responsibilities and men have prescribed responsibilities. So, if a woman knows her right it's going to alleviate the oppression, the persecution, the things that happen to women commonly in machismo societies. So, don't try to tell me I cannot do this when I know I can [laughter]. Example. I want to go to work. If I am maintaining my household in the ways that I have responsibility to do, then I can go to work and when I come back from work I don't have to give $50 \%$ of the rent and $50 \%$ of the utilities, or buy the food. My money is mine, $100 \%$ of it [laughter]. If I want to contribute to the house then I can, but my personality type is that if you tell me that I have to, I get tight, tight, tight [laughter]. If you ask me nicely I'll give you anything, anything, anything. So, if a woman knows her rights, then in Islam, you are protected, you really are... American women understand equal rights [differently], and I am a member of...the 
burning bras...generation. I don't want [American] equal rights. Equal rights means that when the draft comes in, then I'm a part of it, and I don't want to do it, quite personally. In Islam, I have my rights, but they are my rights as a woman, and they are different then rights as a man. But in asserting those rights it prevents many bad things from happening to women in so many machismo societies.

Kim's perspective may be considered somewhat unique, as she is an adult (American) convert and, therefore, is in a unique position to juxtapose a Muslim-lived experience with that of her non-Muslim past. Her understanding of the "roles" and "responsibilities" afforded her as a wife, per Islamic law (Sharia), seemed to make her proud to be a Muslim. Moreover, she also did not shy away from criticizing how "American women understand equal rights," a term she mentioned seventeen times in her above response. Kim also referenced sexuality, employment and finances all in relation to her rights as a woman.

One husband also opined on the misconceptions of female oppression in Islamic communities and prohibitions to enter the workplace:

Omar (Sunni husband): There is a saying and this goes like: "The Heaven is under the feet of the mother." So, try to please your mother if you want to go to Heaven. But you know, in some Arab countries or Muslim countries, we see a lot of [disrespect], at times even in the West. I think there is such a misinterpretation that men are superior to the women. I don't know exactly where it comes from, basically from the misinterpretation of Islam, of the verses or some of the sayings of Prophet [Muhammad]; but I think it`s completely wrong. One of the most basic misinterpretations that can lead to some problems in the marriage is that if man believes it is his right to be superior to the women, then it can definitely lead to problems... Some people believe that Muslim women should not work, or should not go outside in the society. It's a misinterpretation too. For example, the wife of the Prophet was leading an Army, and his previous wife was actually a merchant, she was actually a boss of several hundred men. I mean the practice at the time was very different. But [throughout] the centuries it got misinterpreted, things changed, not always in the correct way.

The perspectives in the two previous comments are consistent with the research of Read, who found that stereotypes of Muslim women in the media are frequently overstated and flawed regarding their freedom to participate and work outside the home, as nearly $40 \%$ of Muslim women surveyed were employed full-time. Read posits that although Muslim women's labor force participation is lower than their non-Muslim counterparts, this is likely due primarily to differences in acculturation between Muslim and non-Muslim populations, not necessarily to oppression generated by Islamic teachings [47-49]. Browning and Clairmont have similarly observed that "for most Muslim women, the question of career versus family is not a choice but an attempt to determine whether any kind of employment will interfere with or somehow even supplant their responsibilities as full time parents” ([60], p. 220). In other words, Islam does not forbid women to work outside the home, but rather it encourages women, who are able, to raise children and maintain the home. Family life is their highest priority. Kalthoom, a Shia Muslim wife, echoed this notion as follows: 
My marriage is my first priority. Prayer is very important and fasting is very important... You have to pray, it is mandatory, and you have to fast; but I think after doing all of that, marriage comes as priority. For woman, marriage and family should come first. Doing social things is very good. Enhancing social life is part of religion, but some people tend to engage in social life so much that they forget about their family. And that is very harmful.

Tamara, a Sunni wife, also spoke about female oppression and the misconception that Islam forbids women to participate in activities outside of the home, especially in the presence of non-kindred men:

Sometimes there is a misconception and misunderstanding [about Muslim women in general or a Muslim woman in particular]. People may think she is oppressed, that she can't do what she wants to do [and that] she can't function as any other woman in society. That is not true. Within boundaries, you can do whatever [you want]. I mean I go and workout. I know some of the women in our community go to the woman wellness center because it is only women. I go and workout at the YMCA with both men and women and I still cover. ${ }^{4}$ I still wear my long sleeves and my scarf, and I do the aerobics.... I am dressed properly. I am not wearing anything revealing. That might be a misconception.

Several participants also acknowledged that misconceptions about women and gender roles in Islam are not only pervasive in non-Muslim communities, but also within Muslim communities. As one example, Burku (a Sunni husband), suggested that ignorance is to blame:

Prophet [Mohammed] used to do housework, he used to cook, he used to make his dress, but [in] today’s Muslim countries and Muslim families, you don't see that at all. Women do almost everything. And they tie this to religion but religion doesn't say that. The problem is that Muslims today don't read very much, and they don't listen very much. So, when the people who speak give the wrong information, everybody has the wrong information. It used to be that Prophet treated his wife [equal], they used to do sports together,...they ran together, they did horse riding. Today you don't see that very much.

Another often-criticized traditional Islamic custom, previously mentioned by Tamara and addressed by several other participants, is the injunction for Muslim women to cover their entire bodies and, in particular, to wear a hijab (i.e., a veil that covers the hair, neck and chest). Several participants directly addressed these criticisms, as illustrated by the following two excerpts:

Izadi (Shia wife): In my opinion, Hijab is not just about clothes... It is a whole institution of separation [between men and women] that was made by the creator of everything... God has set certain standards. According to my religious belief...one of the things is modesty at a level where you have to totally ignore the other gender... That is a sacrifice, especially when you are a teenager.

Jane (Sunni wife): I cover my head. Why do I cover my head? Because in our religion, I do not want men to flirt with me. Let's face it, if I were standing next to a woman in a bikini,

4 The YMCA ("Young Men’s Christian Association”) is a Christian-based community center where local residents can go and exercise or attend various educational or sports classes relating to health, etc. YMCA centers are in thousands of locations worldwide. 
men would lust over her and not over me. I don't want men to lust over me, whether I'm married or not. One of the ways to prevent that is to cover up... I don't call this a sacrifice. Think about all the women who spend hours and hours doing their hair, I don’t have [to do] that... I used to have to get up at the crack of dawn to style. [Now] I can get up and wash it, dry it, braid it, and go. I don't have that pressure or the pressure of wearing fad clothes. I don't think it's a sacrifice in any way. I think I gained beyond my wildest dreams... I feel that in Islam, I have more rights than I did before.

Like Kim, who was referenced at length earlier, Jane converted to Islam. Notice that she too mentioned "rights" and felt that she was afforded more rights after converting to Islam than before converting. Nadia Malik, a writer for the Daily News Herald in Illinois remarked similarly that she felt liberated after deciding to don hijab, a practice she had not been accustomed to observing: "How can I explain to people who see hijab as a tool of oppression that [deciding to wear it] was one of the most liberating experiences of my life?” ([10], p. 38). In addition to the issue of "rights", the question of sacrifice was mentioned. Notice that Izadi, a lifelong Shia Muslim, viewed modesty laws and hijab as a sacrifice, whereas Jane, a convert, remarked: “I don't consider this a sacrifice.” The difference in opinion on this matter as adults may reflect the upbringing of both of these women. It may also be that converts generally observe their new religion more "intensely" than lifelong adherents ([61], p. 94).

While more women seemed to speak up about dress and hijab, a few husbands also shared thoughts on these customs, as illustrated by the following two comments:

Maythan (Shia husband): If a lady has Hijab, that does not mean she does not go to school, or she can't go to work. [To think that way] is hurting you. If you have Hijab, you have to go get more education. Now you are protected. You have more duty.

Mokthar (Shia husband): In a permissive society like American society, you need some extra barriers between you and things that happen there. I am not saying that you need to separate yourself from society itself, but from bad things in society...Having the Hijab is helping us, not only her, but also me to keep away from things we do not like and stick to things we do like.

For these men, Hijab is viewed as both symbolic and functional, although in somewhat different ways than expressed by the women who reported and reflected. Again, as we close with Mokthar's reflection, we see a relational undercurrent and subtle implication: that the Hijab provides a literal and symbolic boundary of modesty and, by extension, marital fidelity.

We have attempted to convey, responsibly and respectfully, these three emergent themes with precision and validity. As illustrated above, most of our participants discussed the perceived impact of Islam on their marriages. Several participants commented that Islam directly impacts even relatively minor aspects of their lives. Many participants were also quick to defend Islam against "misconceptions" that seem to be ubiquitous in non-Muslim cultures. The misconceptions identified in the interviews almost always related to gender roles and the treatment of women, both inside the home and in society. From the reported vantage of our participants, however, the same faith that many Westerners equate with female oppression is held as a potentially unifying force in the marital relationship; and in many other aspects of life. We are reminded of Burr's proposition that: 
It is variation in what people do as a result of their ideals and beliefs about the sacred that determines whether the sacred is helpful or harmful in families, and it is not the mere presence of religion...that makes the difference ([1], p. 17, emphasis in original).

\section{Conclusions}

As addressed near the outset of the article, this study is novel in a number of ways. While a majority of available social science research on the religion-family connection focuses on white Christians raised in the U.S., the present study draws on a religiously and racially diverse (predominantly non-white) sample of married Shia and Sunni Muslim parents residing in the Unites States. These families hail from a variety of nations and regions providing an array of origins and perspectives within Islam.

Studies about Muslim families in the U.S. are rare and severely limited in scope, including the present study. While high quality social research on the influence of Islam has begun to emerge in recent years, largely through the efforts of Abdel-Khalek and colleagues, this research has focused almost exclusively on individual-level, psychological outcomes (e.g., reported happiness, depression, individual well-being, etc.) and not on familial connection, relationships and stability. The present article is among the first to focus on familial and marital topics through the use of in-depth qualitative interviews. Interviewing both partners together, however, may be a limitation to this study. Husbands or wives may be less likely to speak freely in the presence of their spouse. They may suppress, for example, their true thoughts when asked questions about marital conflict or the potential harmful effects of certain religious beliefs and practices. Interviewing couples together, however, may also contain added benefits. Marks et al. suggested that conducting joint interviews "provided a rich context for learning about marriage, marital interaction, and marital processes...[and also] provided the researcher with a front row seat as couples cocreated meaning through narratives” ([62], p. 175).

A final contribution of the study is the effort to give Muslim participants, quite literally, their own voice. While this article's sample is not generalizable and is insufficient for someone to draw a broad and accurate picture of Muslim families, even so, it represents an important initial step. We think it likely that most practicing Muslim individuals and families in the U.S. bear far more resemblance to the individuals and families in this article than they do to Islamic extremists frequently captured in popular Western media. Our hope is that the participants' stories, narratives and reflections will combine to offer a compressed, but valid portrait of some Muslim families in the U.S.; and that this portrait will be facilitative in sensitizing clinicians, therapists, counselors, teachers, religious leaders of other faiths and others as they respectfully interact with Muslim individuals and families.

Although our focus is salutogenic or strengths-focused (as opposed to projecting a deficit model of Islam as typically highlighted in media), our intention is not apologetics, but to offer detailed, first-hand, "insider" perspectives that offer new insight into the hearts, minds and family relationships of the Muslim participants who opened their homes and lives to us. More important than demonstrating the importance of faith in the lives of these families, this study attempts to understand central reasons why and how their lived religion matters to them. In summary, participants reportedly viewed religious practices, rituals, prescriptions and prohibitions as sacred duties, but also reported personal and relational benefits that resulted from their adherence and faith-based action. More specifically, the 
participants indicated that for them (1) "Islam is a way of life"; (2) "Islam is a unifying force" in their marital and familial lives and that (3) Islam outlines "Rights, roles and responsibilities", regarding the treatment of women, in ways that are largely appreciated by this involved sample of women and men who are striving to faithfully walk a Muslim course of life.

We now offer a few additional insights regarding the three identified themes and also suggestions for future research. That many of our participants commented that Islam guides every aspect of life is not surprising. Islam, while not known for having a highly complex theology, is a legalistic religion. Muslims are reminded of their commitment to Islam and the accompanying laws at least five times per day during prayer, for example. The Quran, for many Muslims, seems to be a resource to find answers on how to act and how to proceed through life in a way pleasing to Allah ("God”). It is less viewed as a resource replete with spiritually uplifting stories and moral lessons that help people develop a close "relationship" with the deity, much like the Bible seems to do for many conservative Protestant Christians. While Islam does emphasize moral teachings and stress certain beliefs, it seems to be more concerned with doing. Therefore, it behooves researchers to identify specific laws and customs practiced by most Muslims and subsequently examine how these laws and customs may influence marriage relationships, parent-child relationships and parenting styles. If Islam is as influential in the lives of Muslims as our participants claimed, then scholars must conduct more research on the outcomes of this influence or perceived influence.

Themes two and three address, more specifically, marriage relationships and sensitive issues, like gender roles and the treatment of women. These issues are especially important, because Westerners tend to view Islam negatively, perhaps because the media seems to focus on terrorism and perceived negative customs that affect women in Muslim communities. One problem, however, with the various portrayals of the treatment of women in Western media is that these portrayals do not differentiate between oppression that results from social customs of a particular region, including distortions of Islam that may be prevalent among less educated communities, and oppression that results from Islamic law. As Kim and Jane commented above, they feel that they have more rights as a woman after converting to Islam than they did before converting to Islam. This study is novel, because it examines the issue of gender roles and the treatment of women in a U.S. context. These findings may reflect reality and the ideal of Islam and Muslim couple relationships more accurately than a superficial, journalistic investigation of Islam in a poor, tribal, African context, for example. Researchers must conduct more rigorous studies, both inside and outside of North America, in order to properly address the issues of gender roles and the oppression of women vis-à-vis Islam.

\section{Author Contributions}

Z. Alghafli conducted interviews and analyzed the data. T. Hatch analyzed the data and wrote the following sections: introduction, overview of literature, findings, and a small portion of conclusions. L. Marks conducted interviews and wrote the following sections: method and a large portion of conclusions.

\section{Conflicts of Interest}

The authors declare no conflict of interest. 


\section{References}

1. Wesley R Burr, Loren D. Marks, and Randal D. Day. Sacred Matters: Religion and Spirituality in Families. New York: Routledge, 2012.

2. Kevin Christiano. "Religion and the Family in Modern American Culture." In Family, Religion, and Social Change in Diverse Societies. Edited by Sharon Houseknecht and Jerry Pankhurst. New York: Oxford University Press, 2000.

3. David. C. Dollahite, Loren D. Marks, and Michael A. Goodman. "Families and Religious Beliefs, Practices, and Communities: Linkages in a Diverse and Dynamic Culture Context." In The Handbook of Contemporary Families: Considering the Past, Contemplating the Future. Edited by Marilyn J. Coleman and Lawrence H. Ganong. Thousand Oaks: Sage Publications, 2004, pp. 411-31.

4. Harold G. Koenig, Michael E. McCullough, and David B. Larson. Handbook of Religion and Health. New York: Oxford University Press, 2001.

5. Annette Mahoney. "Religion in Families, 1999-2009: A Relational Spirituality Framework." Journal of Marriage and Family 72 (2010): 805-27.

6. Kenneth I. Pargament, and Annette Mahoney. "Sacred Matters: Sanctification as a Vital Topic for the Psychology of Religion.” The International Journal for the Psychology of Religion 15 (2005): 179-98.

7. Brian J. Grim, and Mehtab S. Karim. "The Future of the Global Muslim Population: Projections for 2010-2030.” Washington: Pew Research Center, 2011.

8. Wen Cheng, William Ickes, and Jared Kenworthy. "The Phenomenon of Hate Crimes in the United States.” Journal of Applied Social Psychology 43 (2013): 761-94.

9. Cynthia Baker. "Globalization and the Cultural Safety of an Immigrant Muslim Community." Journal of Advanced Nursing 57 (2007): 296-305.

10. Yvonne Y. Haddad, Jane I. Smith, and Kathleen M. Moore. Muslim Women in America: The Challenge of Islamic Identity Today. Oxford: Oxford University Press, 2006.

11. James Bell. "The World's Muslims: Religion, Politics and Society.” Washington: Pew Forum on Religion and Public Life, 2013.

12. Myra Macdonald. "Muslim Women and the veil: Problems of image and voice in media representations.” Feminist Media Studies 6 (2006): 7-23.

13. Loren D. Marks, and David C. Dollahite. "Mining the Meanings and Pulling out the Processes from Psychology of Religion's Correlation Mountain.” Psychology of Religion and Spirituality 3 (2011): 181-93.

14. Robert A. Hummer, Richard G. Rogers, Charles B. Nam, and Christopher G. Ellison. "Religious Involvement and U.S. Adult Mortality.” Demography 36 (1999): 273-85.

15. Loren D. Marks. "Religion and Bio-Psycho-Social Health: A Review and Conceptual Model." Journal of Religion and Health 44 (2005): 173-86.

16. Loren D. Marks. "Religion and family relational health: An overview and conceptual model." Journal of Religion and Health 45 (2006): 603-18.

17. Loren D. Marks. “Mental health, religious belief, and 'the terrifying question'.” Journal of Child and Family Studies 15 (2006): 133-39. 
18. Loren D. Marks. "Sacred Practices in Highly Religious Families: Christian, Jewish, Mormon, and Muslim Perspectives.”Family Process 43 (2004): 217-31.

19. David C. Dollahite, and Loren D. Marks. "How Highly Religious Families Strive to Fulfill Sacred Purposes.” In Sourcebook of Family Theory and Research. Edited by Vern L. Bengtson, Alan C. Acock, Katherine R. Allen, Peggye Dillworth-Anderson and David M. Klein. Thousand Oaks: Sage, 2005, pp. 533-41.

20. David C. Dollahite, and Loren D. Marks. "A Conceptual Model of Family and Religious Processes in Highly Religious Families.” Review of Religious Research 50 (2009): 373-91.

21. Yaxin Lu, Loren Marks, and Loredana Apavaloiae. "Chinese Immigrant Families and Christian Faith Community: A Qualitative Study.” Family and Consumer Sciences Research Journal 41 (2012): 118-30.

22. Annette Mahoney, Kenneth I. Pargament, Tracey Jewell, Aaron B. Swank, Eric Scott, Erin Emery, and Mark Rye. "Marriage and the Spiritual Realm: The Role of Proximal and Distal Religious Constructs in Marital Functioning.” Journal of Family Psychology 13 (1999): 321-38.

23. Nathaniel M. Lambert, and David C. Dollahite. "How Religiosity Helps Couples Prevent, Resolve, and Overcome Marital Conflict.” Family Relations 55 (2006): 439-49.

24. Nathaniel M. Lambert, Frank D. Fincham, Loren D. Marks, and Tyler F. Stillman. "Invocations and Intoxication: Does Prayer Decrease Alcohol Consumption?” Psychology of Addictive Behaviors 24 (2010): 209-19.

25. Mark H. Butler, Julie A. Stout, and Brandt C. Gardner. "Prayer as a Conflict Resolution Ritual: Clinical Implications of Religious Couples’ Report of Relationship Softening, Healing Perspective, and Change Responsibility.” American Journal of Family Therapy 30 (2002): 19-37.

26. Loren D. Marks. "Prayer and Marital Intervention: Asking for Divine Help...or Professional Trouble?” Journal of Social and Clinical Psychology 27 (2008): 678-85.

27. Annette Mahoney, Sara A. Pendelton, and Heidi K. Ihrke. "Religious Coping by Children and Adolescents: Unexplored Territory in the Realm of Spiritual Development.” In The Handbook of Spiritual Development in Childhood and Adolescence. Edited by Eugene C. Roehlkepartain. Thousand Oaks: Sage, 2006, pp. 341-54.

28. Kristen Taylor Curtis, and Christopher G. Ellison. "Religious Heterogamy and Marital Conflict: Findings from the National Survey of Families and Households.” Journal of Family Issues 23 (2002): 551-76.

29. Harold G. Koenig, ed. Handbook of Religion and Mental Health. New York: Academic Press, 1998.

30. Annette Mahoney, Kenneth I. Pargament, Nalini Tarakeshwar, and Aaron B. Swank. "Religion in the Home in the 1980s and 1990s: A Meta-Analytic Review and Conceptual Analysis of Links Between Religion, Marriage, and Parenting.” Journal of Family Psychology 15 (2002): 559-96.

31. Amy M. Burdette, Christopher G. Ellison, Darren E. Sherkat, and Kurt A. Gore. "Are There Religious Variations in Marital Infidelity?” Journal of Family Issues 28 (2007): 1553-81.

32. Michael A. Goodman, and David C. Dollahite. "How Religious Couples Perceive the Influence of God in their Marriage.” Review of Religious Research 48 (2006): 141-55.

33. Nathaniel M. Lambert, and David C. Dollahite. “The Threefold Cord Marital Commitment in Religious Couples.” Journal of Family Issues 29 (2008): 592-614. 
34. Richard A. Mackey, and Bernard A. O’Brien. "The Significance of Religion in Lasting Marriages.” Journal of Religion, Spirituality and Aging 18 (2005): 35-63.

35. Linda C. Robinson, and Priscilla W. Blanton. "Marital Strengths in Enduring Marriages.” Family Relations 42 (1993): 38-45.

36. Ahmed M. Abdel-Khalek. "Happiness, Health, and Religiosity: Significant Relations.” Mental Health, Religion and Culture 9 (2006): 85-97.

37. Ahmed M. Abdel-Khalek. "Religiosity, Happiness, Health, and Psychopathology in a Probability Sample of Muslim Adolescents.” Mental Health, Religion and Culture 10 (2007): 571-83.

38. Ahmed M. Abdel-Khalek. "Quality of Life, Subjective Well-Being, and Religiosity in Muslim College Students.” Quality of Life Research 19 (2010): 1133-43.

39. Ahmed M. Abdel-Khalek. "Associations between Religiosity, Mental Health, and Subjective Well-Being among Arabic Samples from Egypt and Kuwait.” Mental Health, Religion and Culture 15 (2012): 741-58.

40. Ahmed M. Abdel-Khalek. "Subjective Well-being and Religiosity: A Cross-Sectional Study with Adolescents, Young and Middle-Age Adults.” Mental Health, Religion and Culture 15 (2012): 39-52.

41. Ahmed M. Abdel-Khalek, and David Lester. "Constructions of Religiosity, Subjective Well-Being, Anxiety, and Depression in Two Cultures: Kuwait and USA.” International Journal of Social Psychiatry 58 (2012): 138-45.

42. Dena Hassouneh-Phillips. “American Muslim Women's Experiences of Leaving Abusive Relationships.” Health Care for Women International 22 (2001): 415-32.

43. Dean Hassouneh-Phillips. "Strength and Vulnerability: Spirituality in Abused American Muslim Women’s Lives.” Issues in Mental Health Nursing 24 (2003): 681-94.

44. Lynne L. Manganaro, and Nicholas O. Alozie. "Gender Role Attitudes: Who Supports Expanded Rights for Women in Afghanistan?” Sex Roles 64 (2011): 516-29.

45. John P. Bartkowski, and Jen’nan Ghazal Read. “Veiled Submission: Gender, Power, and Identity among Evangelical and Muslim Women in the United States.” Qualitative Sociology 26 (2003): 71-92.

46. Anna Piela. “Muslim Women’s Online Discussions of Gender Relations in Islam.” Journal of Muslim Minority Affairs 30 (2010): 425-35.

47. Jen'nan Ghazal Read. "Challenging Myths of Muslim Women: The Influence of Islam On Arab-Arnerican Women’s Labor Force Activity.” The Muslim World 92 (2002): 19-37.

48. Jen'nan Ghazal Read. "The Sources of Gender Role Attitudes among Christian and Muslim Arab-American Women.” Sociology of Religion 64 (2003): 207-22.

49. Jen'nan Ghazal Read. "Family, Religion, and Work among Arab American women.” Journal of Marriage and Family 66 (2004): 1042-50.

50. Kerry Daly. “The Fit between Qualitative Research and Characteristics of Families.” In Qualitative Methods in Family Research. Edited by Jane Frances Gilgun, Kerry Daly, and Gerald Handel. Newbury Park: Sage, 1992, pp. 3-11.

51. Jane Frances Gilgun, Kerry Daly, and Gerald Handel. Qualitative Methods in Family Research. Newbury Park: Sage Publications, 1992. 
52. Anselm Strauss, and Juliet Corbin. Basics of Qualitative Research: Grounded Theory Procedures and Techniques. Newbury Park: Sage, 1990.

53. Loren D. Marks. "Illuminating the Interface between Families and Faith.” PhD dissertation, Newark, Delaware: University of Delaware, 2001.

54. David C. Dollahite, Loren D. Marks, and Michael M. Olson. "Fathering, Faith, and Family Therapy: Generative Narrative Therapy with Religious Fathers.” Journal of Family Psychotherapy 13 (2002): 263-94.

55. Loren D. Marks, Katie E. Cherry, and Jennifer L. Silva. "Faith, Crisis, Coping, and Meaning Making after Katrina: A Qualitative, Cross-Cohort Examination.” In Lifespan Perspectives on Natural Disasters: Coping with Katrina, Rita and other Storms. Edited by Katie E. Cherry. New York: Springer, 2009, pp. 195-215.

56. David C. Dollahite, Loren D. Marks, and Michael M. Olson. "Faithful Fathering in Trying Times: Religious Beliefs and Practices of Latter-day Saint Fathers of Children with Special Needs.” The Journal of Men's Studies 7 (1998): 71-93.

57. Kerry Daly. "Parenthood as Problematic: Insider Interviews with Couples Seeking to Adopt.” In Qualitative Methods in Family Research. Edited by Jane Frances Gilgun, Kerry Daly, and Gerald Handel. Newbury Park: Sage, 1992, pp. 103-25.

58. Elizabeth B. Farnsworth. "Reflexivity and Qualitative Family Research: Insider's Perspectives in Bereaving the Loss of a Child.” Marriage and Family Review 24 (1997): 399-415.

59. Mary Betsy Garrison, Loren D. Marks, Frances C. Lawrence, and Bonnie Braun. "Religious Beliefs, Faith Community Involvement and Depression: A Study of Rural, Low-Income Mothers.” Women and Health 40 (2005): 51-62.

60. Don S. Browning, and David A. Clairmont, eds. American Religions and the Family: How Faith Traditions Cope with Modernization and Democracy. New York: Columbia University Press, 2007.

61. Roberta G. Sands. “The Social Integration of Baalei Teshuvah.” Journal for the Scientific Study of Religion 48 (2009): 86-102.

62. Loren D. Marks, Katrina Hopkins, Cassandra Chaney, Pamela A. Monroe, Olena Nesteruk, and Diane D. Sasser. “'Together, We Are Strong’: A Qualitative Study of Happy, Enduring African American Marriages.” Family Relations 57 (2008): 172-85.

(C) 2014 by the authors; licensee MDPI, Basel, Switzerland. This article is an open access article distributed under the terms and conditions of the Creative Commons Attribution license (http://creativecommons.org/licenses/by/3.0/). 